\title{
Uniphasic Insulin Responses to Secretin Stimulation in Man
}

\author{
Roger L. Lerner and Daniel Porte, Jr. \\ From the University of Washington School of Medicine and Veterans Administration \\ Hospital, Seattle, Washington 98108
}

\begin{abstract}
A B S T R A C T Secretin-stimulated insulin release was studied in normal subjects. In response to rapid intravenous injections (pulses) of secretin, insulin levels reached a peak between 2 and $5 \mathrm{~min}$ and returned to basal levels with $15 \mathrm{~min}$. In contrast to large glucose pulses, increasing secretin pulses did not elicit sustained or prolonged insulin responses. In addition, insulin responses to a pulse and infusion were essentially identical with that of a pulse alone. Increasing secretin pulses given in 1 day were associated with decreasing insulin responses but not when the same pulses of secretin were given over a 2 day period. When time was the sole variable, insulin responses progressively decreased after identical $15-\mathrm{U}$ secretin pulses given every $30 \mathrm{~min}$, but were unchanged when the interval was $105 \mathrm{~min}$. These observations indicate that secretin in contrast to glucose stimulates insulin release which is uniphasic. They suggest that release occurs only from a stored, readily available pool. This insulin pool appears to be relatively small and can be discharged faster than it refills.
\end{abstract}

\section{INTRODUCTION}

Insulin secretion has been noted to be significantly increased after an oral glucose load compared with an identical amount of glucose given intravenously (1). Recent investigation has focused on gastrointestinal factors in an effort to explain this difference. Of the intestinal hormones studied, secretin has been found among the most potent insulin-stimulating substances (2). It has been shown to stimulate insulin release both in vitro and in vivo $(3,4)$, the accumulated data suggesting that biologically active insulin is released very rapidly following either intravenous secretin administration (2) or by substances known to stimulate endogenous secretin release (5).

This work was presented in part at the Western Section, American Federation for Clinical Research, Carmel, Calif., January 1970.

Received for publication 30 June 1970 and in revised form 4 August 1970.
In the past several years the concept of insulin release following glucose has been modified from an assumption of simple linearity to a more complex multiphasic secretory pattern $(6,7)$. We have recently proposed a two pool mechanism which attempts to resolve some of the ambiguities of glucose-stimulated insulin release in man $(8,9)$. The first of these pools is a small storage pool of readily available insulin which responds immediately to changes in the blood glucose level. The second pool responds more slowly to changes in glucose metabolism and its secetory pattern is manifested by the basal and steady-state insulin levels.

The similarity between our observations of acute insulin responses to glucose $(8,10)$ and the rapid secretin-stimulated responses reported by others $(4,5)$, prompted the further characterization of the pattern of insulin release following secretin administration.

\section{METHODS}

All subjects had no family history of diabetes, were less than $115 \%$ ideal body weight according to Metropolitan Life Insurance Company tables, and were studied at bed rest on the Clinical Research Center of the University Hospital after overnight $(12 \mathrm{hr})$ fast. After placement of a butterfly needle in an antecubital vein and its patency maintained by a slow drip of $0.85 \%$ saline, four base line samples for glucose and immunoreactive insulin (IRI) were obtained during the following $60 \mathrm{~min}$. Normal subjects were separated into five groups. The first group of five subjects received rapid intravenous injections (pulses) of secretin ${ }^{1}$ every $75 \mathrm{~min}$ in the following doses: $10,25,75,150$, and $300 \mathrm{U}$. The second group of four subjects received secretin pulses over 2 days after a $60 \mathrm{~min}$ basal period on each day. The 1 st day $10-\mathrm{U}$ and $75-\mathrm{U}$ pulses were administered; on the 2nd day a $300 \mathrm{U}$ pulse of secretin was administered. A third group of four subjects were given a priming secretin dose of $15 \mathrm{U}$ immediately followed by a $25 \mathrm{~min}$ infusion of $3 \mathrm{U} / \mathrm{min}$ for a total of $90 \mathrm{U}$. This method has been shown by Chisholm, Young, and Lazarus to achieve reasonably constant plasma secretin levels as measured by an immunoassay (5). A fourth group of six subjects received only $15-\mathrm{U}$ pulses during the following time intervals: the first two pulses were separated by 105 min; the second, third, and fourth pulses were each sepa-

${ }^{1}$ Obtained from Dr. Jorpes, Dept. of Chemistry, Karolinska Institutet, Stockholm, Sweden. 

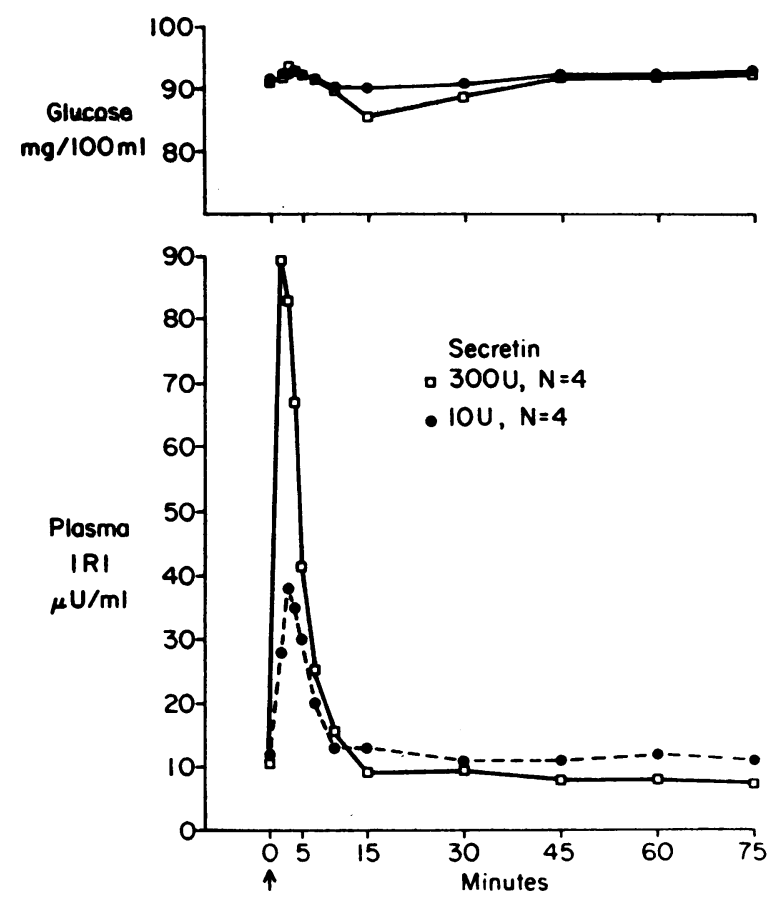

Figure 1 Mean glucose and insulin responses to small and large secretin pulses.

rated by a $30 \mathrm{~min}$ interval. A fifth group of 16 normal subjects received 5-g glucose pulses. After the insulin and glucose levels had returned to essentially the prestimulated level, eight of these subjects received a $40 \mathrm{~g}$ glucose pulse.

The injection time in all studies was within $15 \mathrm{sec}$ except the $40 \mathrm{~g}$ glucose pulse which was administered in $30-40 \mathrm{sec}$. Samples were obtained at 2, 3, 4, 5, 7, 10, and $15 \mathrm{~min}$ and every $15 \mathrm{~min}$ thereafter, using the midpoint of injection as zero time for each pulse. Plasma glucose was measured by the AutoAnalyzer ferricyanide method and serum insulin, by a modification of a double antibody technique (11).

Calculations. Estimates of the acute insulin response were determined by the mean increment above basal from the 2 through $5 \mathrm{~min}$ insulin values $\left(2-5^{\prime}\right.$ mean $\Delta$ IRI $\left.\mu \mathrm{U} / \mathrm{ml}\right)$.

\section{RESULTS}

I. General characteristics of the insulin response to secretin compared to that of glucose. Following a small $(10 \mathrm{U})$ secretin pulse plasma IRI levels rose rapidly, and were detectable at 2 min with a peak within $5 \mathrm{~min}$ followed by a rapid return to basal levels by $15 \mathrm{~min}$ (Fig. 1). With a large (300 U) secretin pulse (Fig. 1), the plasma insulin response was greater but the timing was identical with that noted above. Although a similar early rapid insulin response was seen to a $5 \mathrm{~g}$ glucose pulse, the response to a $40 \mathrm{~g}$ glucose pulse (Fig. 2), in marked contrast, remained elevated much longer than the total $15 \mathrm{~min}$ secretin response, indicating a major dif-

\footnotetext{
${ }^{2}$ Data in preparation.
}

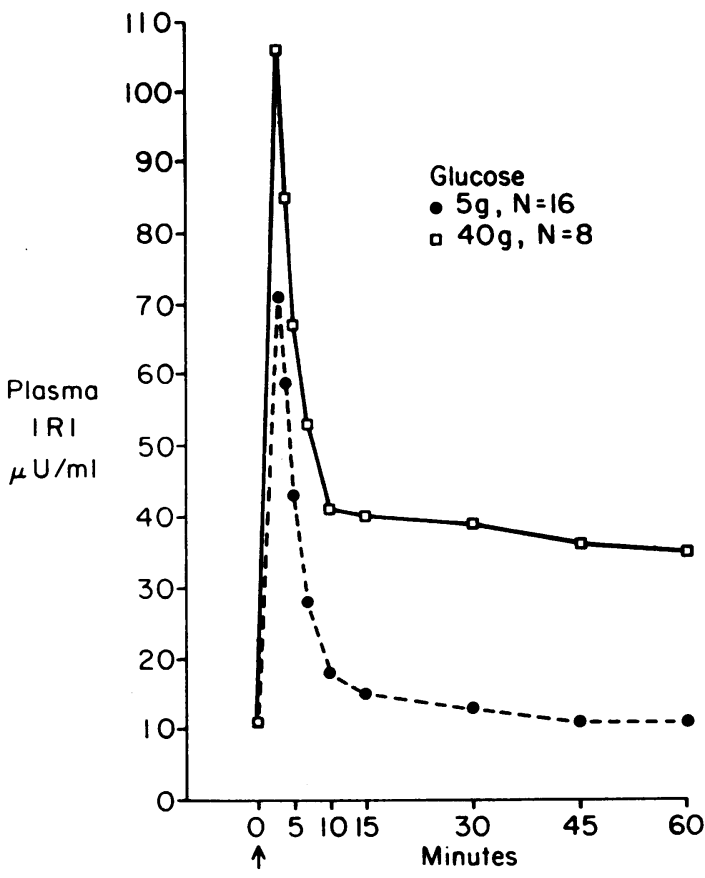

Figure 2 Mean insulin responses to small and large glucose pulses.

ference in the later phases of the insulin response to large glucose pulses.

Although no change in plasma glucose was observed to the $10 \mathrm{U}$ secretin pulse, the $300 \mathrm{U}$ secretin pulse was associated with a decline in the plasma glucose level between 7 and $30 \mathrm{~min}$, which was statistically significant $(P<0.05)$ at $15 \mathrm{~min}$.

II. The acute insulin response to a pulse vs. a constant secretin stimulus. The rapid insulin output following a $15 \mathrm{U}$ pulse in six normal subjects was compared with the insulin response subsequent to a $15 \mathrm{U}$ secretin pulse

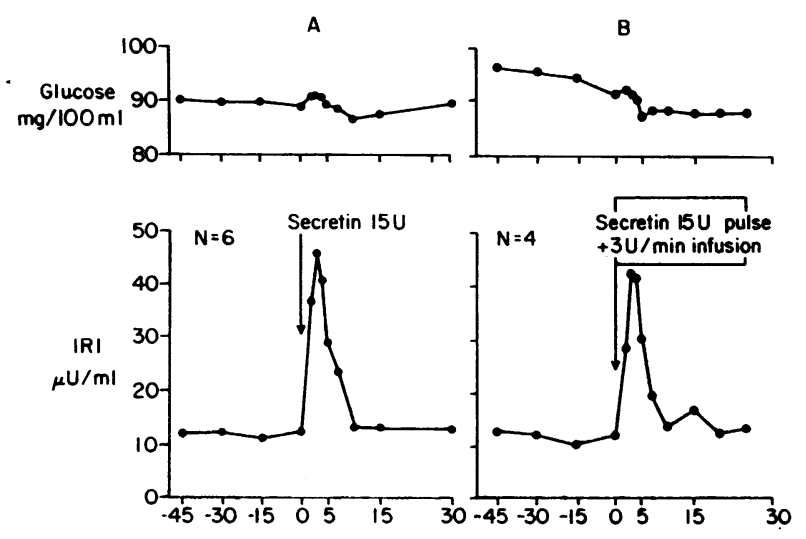

Figure 3 Mean insulin responses to a secretin pulse (A) and pulse plus infusion (B). 


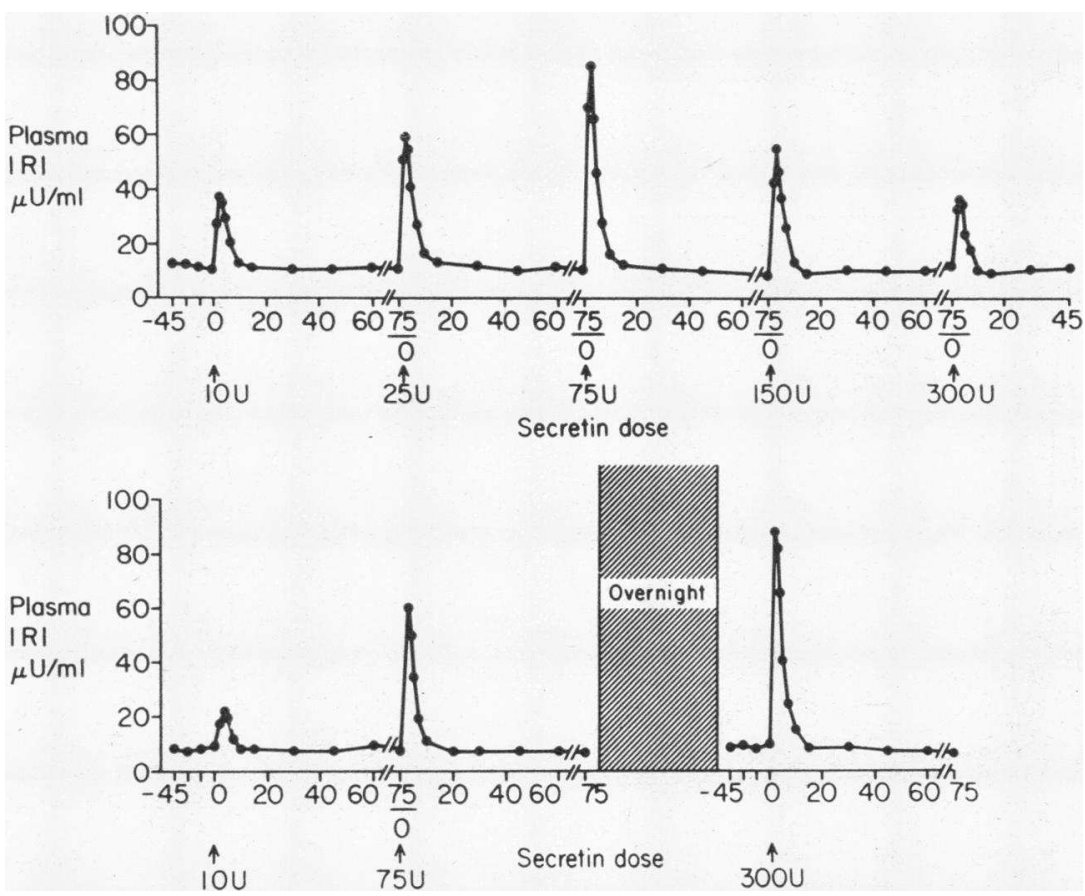

Figlre 4 Mean insulin responses to graded secretin pulses given during a 1 day study (top) and during a 2 day study (bottom).

plus a $3 \mathrm{U} / \mathrm{min}$ infusion for $25 \mathrm{~min}$ in another group of four normal subjects (Fig. 3 ). The transient characteristic insulin response following a $15 \mathrm{U}$ was unaltered despite continuously elevated secretin levels by a pulse plus infusion.

III. The effect of varying both time and secretin loads on the acute insulin response. When secretin was given at 75-min intervals in increasing amounts on 1 day, the acute insulin responses rose in parallel with the dose until the $75 \mathrm{U}$ pulse was given. Beyond this level there was a uniform and significantly decreased insulin output to both the $150-\mathrm{U}$ and $300-\mathrm{U}$ secretin pulses (Fig. 4, top). When the same size pulses were given over a 2 day period to another group of four normal subjects (Fig. 4, bottom), the acute insulin responses increased with the increasing secretin stimuli. The insulin response to $300 \mathrm{U}$ when given on the 2 nd day of a 2 day study (Table I) was significantly $(P<0.05)$ increased, indicating that the time between injections was a critical variable in the magnitude of the insulin response.

$I V$. The effect of time on the insulin response to identical pulses of secretin. When $15-U$ secretin pulses were separated by $105 \mathrm{~min}$ the mean peak insulin responses in six normal subjects were identical. However, with subsequent repetitive administration of secretin pulses every $30 \mathrm{~min}$ there was a progressive fall in the acute insulin response which was statistically significant $(P<0.05)$ by the final (fourth) $15 \mathrm{U}$ pulse (Fig. 5).

\section{DISCUSSION}

Minor decreases in the plasma glucose occur with secretin pulses; the nadir is usually seen between 7 and 30 min. The nadir always appears after the peak insulin response and with increasing secretin pulses and concomitant increased insulin output, the fall of the plasma glucose level tends to be greater. Simultaneous injections of glucose and secretin have been associated with an increased insulin response and a more rapid glucose disappearance $\left(\mathrm{K}_{\mathbf{8}}\right)$ than with the same dose of glucose given alone (2), consistent with the concept that secretin is probably stimulating release of a biologically active insulin. In the present studies only a relatively minor fall in plasma glucose levels occurred at insulin levels comparable to those seen with $20 \mathrm{~g}$ of glucose. There are at least two possible explanations for the small decrease in plasma glucose: either these levels of insulin may not significantly enhance peripheral plasma glucose disposal as has been suggested by Meade, Kneubuhler, Barboriak, and Schulte, who infused small amounts of insulin into a peripheral or the portal vein of dogs (12); or secretin may stimulate both the release of insulin and the mobilization of hepatic glycogen stores, properties characteristic of glucagon. The latter possibility, although undocumented, is suggested by the fact that secretin and glucagon share common amino acid sequences, and are both lipolytic in vitro (13). 
TABLE I

Mean 2-5' $\triangle I R I$ Response to Varying Doses of Secretin on 1 or 2 Days

One Day Study

\begin{tabular}{lcccccc}
\hline & & \multicolumn{5}{c}{ Secretin dose } \\
\cline { 3 - 7 } Subject & Basal* & $10 \mathrm{U}$ & $25 \mathrm{U}$ & $75 \mathrm{U}$ & $150 \mathrm{U}$ & $300 \mathrm{U}$ \\
\hline & $\mu U / m l$ & & \multicolumn{5}{c}{$\mu U / m l$} \\
D. J. & 12.8 & 21.4 & 37.5 & 47.8 & 34 & 19.5 \\
P. K. & 11.2 & 33 & 66.5 & 80.5 & 50.5 & 22.3 \\
J. H. & 8.0 & 6.5 & 14.8 & 21.3 & 8.5 & 8 \\
G. S. & 16.3 & 21.2 & 44.3 & 75.5 & 47.3 & 21.5 \\
Mean & 12.0 & 20.5 & 40.8 & 56.3 & $35.1 \ddagger$ & $17.8 \S$ \\
SEM & 1.5 & 4.7 & 9.2 & 11.9 & 8.3 & 2.9
\end{tabular}

Two Day Study

\begin{tabular}{|c|c|c|c|c|c|}
\hline \multirow[b]{3}{*}{ Subject } & \multicolumn{3}{|c|}{ 1st day } & \multicolumn{2}{|c|}{ 2nd day } \\
\hline & \multicolumn{3}{|c|}{ Secretin dose } & \multicolumn{2}{|c|}{$\begin{array}{l}\text { Secretin } \\
\text { dose }\end{array}$} \\
\hline & Basal* & $10 \mathrm{U}$ & $75 \mathrm{U}$ & Basal* & $300 \mathrm{U}$ \\
\hline & $\mu U / m l$ & \multicolumn{2}{|c|}{$\mu U / m l$} & \multicolumn{2}{|c|}{$\mu U / m l$} \\
\hline H. M. & 8.5 & 24.5 & 62.5 & 9 & 99 \\
\hline T. C. & 7.0 & 6.0 & 19.5 & 6.8 & 50.9 \\
\hline R. M. & 6.0 & 8.3 & 37.8 & 8.0 & 54.8 \\
\hline D. T. & 12.0 & 11.8 & 37.3 & 15.5 & 36.8 \\
\hline Mean & 8.3 & 12.6 & 39.3 & 9.8 & $60.4 \|$ \\
\hline SEM & 1.1 & 3.6 & 7.6 & 1.7 & 11.6 \\
\hline
\end{tabular}

* Mean of four determinations.

‡ Significantly decreased, $P<0.02$, compared with $75 \mathrm{U}$ responses, paired $t$ test.

§ Significantly decreased, $P<0.05$, compared with $75 \mathrm{U}$ responses, paired $t$ test.

|| Significantly increased, $P<0.05$, compared with $300 \mathrm{U}$ responses during the one day study by $t$ test.

Confirming other studies $(2,4,5)$, the present data clearly demonstraate that secretin, like glucose, stimulates rapid insulin release. The peak insulin response to a given pulse of secretin occurs within $5 \mathrm{~min}$, usually at 2 or $3 \mathrm{~min}$, similar to its responses to glucose. Allowing for a 2-3 min venous recirculation time the rapid insulin output to secretin would appear to be an almost instantaneous phenomenon at the islet cell. This would suggest that secretin is stimulating a storage pool of insulin which is available for immediate release, similar to the rapid insulin response to glucose.

With larger doses of glucose the insulin response after the immediate peak output continues for a considerable period of time (14). This continued insulin release may be either from further secretion from the storage pool or from another insulin pool as yet undefined. In contrast, the duration of insulin release to larger doses of

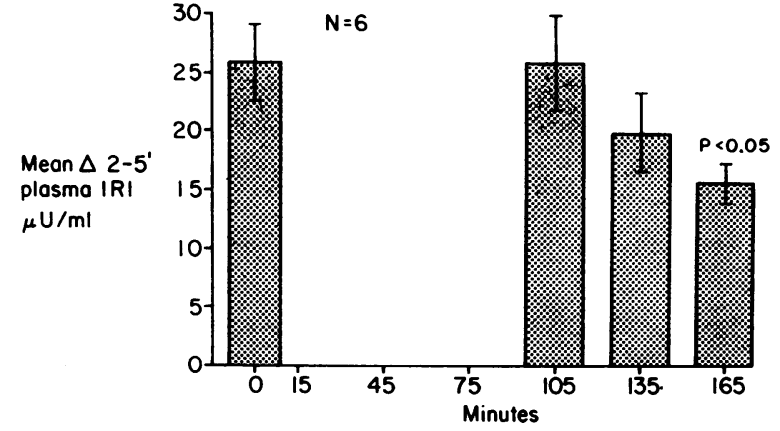

FIGURE 5 Mean incremental insulin responses to identical (15 U) secretin pulses given at two different time intervals.

secretin remains unaltered, implying that secretin stimulates release from only a small stored insulin pool. Moreover, this stimulation is not sustained in spite of large doses $(300 \mathrm{U})$ of secretin, or continued secretin infusion which would maintain blood secretion levels for greater than $15 \mathrm{~min}(5)$. This characteristically uniphasic response also suggests that secretin stimulates insulin release only from a stored pool. The data from the results of the pulse infusion studies reported here are similar to those found by Boyns, Jarrett, and Keen (15) but different from the observations of Chisholm et al. (5), who reported pulse infusion studies in two subjects. The latter group found a continuous relatively unchanged insulin secretion in one subject and relatively steady insulin secretion which increased by the end of the infusion in another. The differences between the present data and that of Chisholm et al. are not readily ap. parent, except that the present study employed a totil dose of $90 \mathrm{U}$, as opposed to $30 \mathrm{U}$ by Chisholm et al. Since the insulin responses increase with increasing secretin pulses of 10,25 , and $75 \mathrm{U}$ (Table I), and the sum of these pulses is greater than the total quantity of secretin given by the present pulse infusion study, the differences in total dose appear not to be a critical factor.

The fall in insulin responses to increasing secretin pulses during a 1 day study suggests that the pool of insulin available to secretin stimulation is linited, the effect of increasing secretin pulses being to diminish the response from this stored pool of insulin at a rate faster than required for refilling of this pool. That time may be critical is evident from the experiments in which the secretin doses are given over a 2 day period. Parallel increases of the acute insulin response to the $10-\mathrm{U}$ and $75-U$ pulses are seen in both the 1 and 2 day study, but the responses to the $300 \mathrm{U}$ pulse on the 2 nd day of the 2 day study are greater than those to the identical pulse given during the 1 day study.

The effects of time were independently examined by administering identical ( $15 \mathrm{U})$ secretin pulses at two 
different time intervals. Although the acute insulin response was unchanged when pulses were separated by $105 \mathrm{~min}$, it progressively decreased when one interval was shortened to $30 \mathrm{~min}$. These observations suggest that the insulin responses are either derived from a small storage pool which can be depleted faster than it refills or that the sensitivity of the islet response to repetitive secretin stimulation is altered. The net effect of either possibility is a functionally depleted insulin pool.

The dose response curve for the 2 day study is curvilinear and appears remarkably similar to that seen when the acute insulin response to glucose is plotted against the glucose stimulus using $0.5-$ to $40-\mathrm{g}$ pulses (10). This curve is consistent with release of insulin from a small storage pool with a dose response curve characteristic of drug receptor interactions (16).

\section{ACKNOWLEDGMENTS}

This investigation was supported in part by U. S. Public Health Service Research Grant AM 12829, Training Grant AM 05498, Research Career Development Award 1K4 AM 8865 (Dr. Porte), Research Fellowship AM 40872 (Dr. Lerner), and the NIH Clinical Research Center facility of the University Hospital (FR-37), Seattle, Wash.

\section{REFERENCES}

1. Elrick, H., L. Stimmler, D. J. Hlad, Jr., and Y. Arai. 1964. Plasma insulin response to oral and intravenous glucose administration. J. Clin. Endocrinol. Metab. 24: 1076.

2. Dupre, J., J. D. Curtis, R. H. Unger, R. W. Waddell, and J. C. Beck. 1969. Effects of secretin, pancreozymin, or gastrin on the response of the endocrine pancreas to administration of glucose or arginine in man. J. Clin. Invest. 48: 745.

3. Pfeiffer, E. F., M. Telib, J. Ammon, F. Melani, and H. Ditschiet. 1965. Direkte Stimulierung der Insulin- sekretion in virto durch Sekretin. Deut. Med. Wochenschr. 90: 1663.

4. Dupre, J., L. Rojar, J. J. White, R. H. Unger, and J. C. Beck. 1966. Effects of secretin on insulin and glucagon in portal and peripheral blood in man. Lancet. 2: 26.

5. Chisholm, D. J., J. D. Young, and L. Lazarus. 1969. The gastrointestinal stimulus to insulin release. I. Secretin. J. Clin. Invest. 4: 1453.

6. Cerasi, E., and R. Luft. "What is inherited-what is added" hypothesis for pathogenesis of diabetes mellitus. Diabetes. 16: 615 .

7. Curry, D. L., L. L. Bennett, and G. M. Grodsky. 1968. The dynamics of insulin secretion by the isolated perfused rat pancreas. Endocrinology. 83: 572.

8. Porte, D., Jr., and A. Pupo. 1969. Insulin responses to glucose: evidence for a two pool system in man. J. Clin. Invest. 48: 2309.

9. Porte, D., Jr., and J. D. Bagdade. 1970. Human insulin secretion: an integrated approach. Annu. Rev. Med. 21: 219.

10. Lerner, R. L., and D. Porte, Jr. 1970. The acute insulin response to intravenous glucose: a non-linear relationship. Clin. Res. $17:$ 186. (Abstr.)

11. Morgan, C. R., and A. Lazarow. 1963. Immunoassay of insulin: two antibody system. Plasma levels of normal, subdiabetic and diabetic rats. Diabetes. 12: 115.

12. Meade, R. C., H. A. Kneubuhler, J. J. Barboriak, and W. J. Schulte. 1969. Absence of glucose response to physiologic levels of serum insulin. Diabetes. 18: 397.

13. Rudman, D., and A. E. Del Rio. 1969. Lipolytic activity of synthetic porcine secretin. Endocrinology. 85: 2144.

14. Lerner, R. L., and D. Porte, Jr. 1970. Secretin: a non sustained stimulator of insulin release. Clin. Res. 17: 123. (Abstr.)

15. Boyns, D. R., R. J. Jarrett, and H. Keen. 1967. Brit. Med.J. 2: 676 .

16. Rigg, D. S. 1963. The Mathematical Approach to Physiological Systems. The Williams \& Wilkins Company, Baltimore. 287. 